University of Nebraska - Lincoln

DigitalCommons@University of Nebraska - Lincoln

2008

\title{
Effectiveness of Lethal, Directed Wolf-Depredation Control in Minnesota
}

\author{
Elizabeth Harper \\ University of Minnesota \\ William J. Paul \\ United States Department of Agriculture, Animal and Plant Health Inspection Service of Wildlife Services \\ L. David Mech \\ USGS Northern Prairie Wildlife Research Center, david_mech@usgs.gov \\ Sanford Weisberg \\ University of Minnesota, Minneapolis, sandy@umn.edu
}

Follow this and additional works at: https://digitalcommons.unl.edu/usgsnpwrc

Part of the Other International and Area Studies Commons

Harper, Elizabeth; Paul, William J.; Mech, L. David; and Weisberg, Sanford, "Effectiveness of Lethal, Directed Wolf-Depredation Control in Minnesota" (2008). USGS Northern Prairie Wildlife Research Center. 99.

https://digitalcommons.unl.edu/usgsnpwrc/99

This Article is brought to you for free and open access by the US Geological Survey at DigitalCommons@University of Nebraska - Lincoln. It has been accepted for inclusion in USGS Northern Prairie Wildlife Research Center by an authorized administrator of DigitalCommons@University of Nebraska - Lincoln. 


\title{
Effectiveness of Lethal, Directed Wolf-Depredation Control in Minnesota
}

\author{
ELIZABETH K. HARPER, University of Minnesota, Department of Fisheries, Wildlife and Conservation Biology, 1980 Folwell Avenue, St. Paul, MN \\ 55108, USA \\ WILLIAM J. PAUL, United States Department of Agriculture, Animal and Plant Health Inspection Service of Wildlife Services, 34912 U.S. Highway 2, \\ Grand Rapids, MN 55744, USA \\ L. DAVID MECH, ${ }^{\mathbf{1 , 2}}$ United States Geological Survey, Northern Prairie Wildlife Research Center, $871137^{\text {th }}$ Street SE, Jamestown, ND 58401, USA \\ SANFORD WEISBERG, University of Minnesota, School of Statistics, 312 Ford Hall, 224 Church Street SE, Minneapolis, MN 55455, USA
}

\begin{abstract}
Wolf (Canis lupus) depredations on livestock in Minnesota, USA, are an economic problem for many livestock producers, and depredating wolves are lethally controlled. We sought to determine the effectiveness of lethal control through the analysis of data from 923 government-verified wolf depredations from 1979 to 1998 . We analyzed the data by 1) assessing the correlations between the number of wolves killed in response to depredations with number of depredations the following year at state and local levels, and 2) the time to the next depredation. No analysis indicated that trapping wolves substantially reduced the following year's depredations at state or local levels. However, more specific analyses indicated that in certain situations, killing wolves was more effective than no action (i.e., not trapping). For example, trapping and killing adult males decreased the re-depredation risk. At sheep farms, killing wolves was generally effective. Attempting to trap, regardless of the results, seemed more effective at reducing depredations than not trapping, suggesting that mere human activity near depredation sites might deter future depredations. (JOURNAL OF WILDLIFE MANAGEMENT 72(3):778-784; 2008)
\end{abstract}

DOI: $10.2193 / 2007-273$

KEY WORDS Canis lupus, control, depredations, livestock, management, Minnesota, wolf.

Lethal control of wolves (Canis lupus) that kill livestock has been an issue for humans as long as humans and their livestock have coexisted with wolves. In the lower 48 United States, persecution of wolves led to their near elimination by the 1960s (Mech 1970). In 1974, wolves were fully protected throughout the 48 United States by the Endangered Species Act of 1973, at which time 700-950 wolves remained in northern Minnesota, plus a small population on Isle Royale, Michigan (Mech 1986, Fuller et al. 1992). Minnesota wolves then increased and expanded their range, were reclassified to threatened in 1978 (Fritts 1982), and were removed from the Endangered Species List in March 2007. Minnesota is now responsible for wolf management in that state.

As wolf populations increased, they saturated wilderness and semi-wilderness areas, where they fed primarily on white-tailed deer (Odocoileus virginianus), and expanded into areas of higher human and livestock concentrations (Fuller et al. 1992, Mech 2001). Livestock depredations increased from 16 in 1979 to 145 in 1998, primarily in the western edge of wolf range (Harper et al. 2005). If wolves continue to increase, livestock depredations may also increase (Mech 1998, 2001).

Increasing wolf depredations on livestock are a concern to farmers, resource managers, agricultural officials, environmentalists, and legislators. Although nonlethal methods have been proposed, none has consistently prevented wolf depredations (Fritts 1982, Fritts et al. 1992), although most have not been extensively tested (Mech et al. 1996). The

\footnotetext{
${ }^{1}$ E-mail:mechx002@umn.edu

2 Present address: The Raptor Center, 1920 Fitch Avenue, University of Minnesota, St. Paul, MN 55108, USA
}

United States Fish and Wildlife Service (USFWS) began lethal control in 1978 (Fritts 1982), but in 1986, Congress transferred the depredation control program to the United States Department of Agriculture, Animal and Plant Health Inspection Service, Animal Damage Control (Fritts et al. 1992), later renamed Wildlife Services (WS).

Under the WS system, farmers who believed their livestock was killed by wolves contacted either their Minnesota Department of Natural Resources (MNDNR) conservation officer or WS. Within 48 hours MNDNR or WS personnel investigated. If they determined that the livestock was killed by a wolf, WS initiated trapping to catch the depredating wolf or wolves with foot-hold traps or neck snares. They limited trapping to within $0.8 \mathrm{~km}$ of the property boundary (USFWS 1985; modification of $14 \mathrm{Jul}$ court order by Judge M. Lord, 2 May 1985) and usually to 15 days (Paul 2001). They checked traps daily, and shot captured wolves. They released pups captured before 1 August, but euthanized those captured after 1 August (USFWS 1985; modification of 14 Jul court order by Judge M. Lord, 2 May 1985). Sometimes WS did not trap; other times, they used nonlethal prevention methods such as strobe-lights or sirens instead (Paul 2001).

Lethal control has seemed effective but has never been assessed in depth. Fritts et al. (1992), using Minnesota data from 1979 to 1986, found that removing depredating wolves did not reduce total depredations in wolf range but may have reduced depredations at some farms (Fritts et al. 1992). Conversely, simulation of various wolf removal strategies suggested that the reactive, WS type of control would reduce depredations by $\geq 40 \%$ (Haight et al. 2002). Considering advances in trapping techniques and devices, the increase in wolf range (Berg and Benson 1999) and in 
wolf depredations (Harper et al. 2005), changes in farm management, and the delisting of wolves in Minnesota, an in-depth evaluation of the effectiveness of directed, lethal depredation control is needed.

We sought to determine if lethal, directed wolf-depredation control in Minnesota reduced depredations and if trapping different ages, sexes, and numbers of wolves influenced control effectiveness. We tested 3 main hypotheses. First, earlier workers had found that fewer recurrent depredations occurred after unsuccessful control than after successful control, so we hypothesized that these findings were caused by researchers including data from the edge of wolf range where only transient wolves depredated. Second, we hypothesized that killing more wolves one year would lead to fewer depredations the next year. Third, we hypothesized that killing wolves would increase time to next depredation or decrease depredation-recurrence rate. In addition to calculating effectiveness for all livestock combined at the state level as Fritts et al. (1992) did, we assessed effectiveness by livestock species at state, local, and farm levels. We also added a reference group of cases where trapping did not occur, assessed the possible effects of season, and calculated recurrence rates. The data presented here complement those of Fritts et al. (1992), and add additional insight into the effectiveness of lethal wolfdepredation control in Minnesota.

\section{METHODS}

We used a database of 20 years of verified wolf-depredation reports and wolf trapping data compiled by the USFWS (1979-1985) and WS (1986-1998). Data included information on the location (township, range, and section) and date of the complaint, dates the USFWS or WS trapped wolves, type of livestock killed (cattle, turkeys, or sheep only), and the sex, age (ad, ad-yearling, yearling, and pup), and number of wolves trapped (killed or released) in response to each depredation. We only used complaints for which government personnel had verified that wolves had killed livestock. If there was any doubt we did not include the complaint in our analysis. We excluded released pups, unless noted, because they were not removed from the population.

The database contained 923 verified depredations at 434 different farms, with 1,440 wolves killed. We considered multiple depredations at the same farm as separate events unless otherwise noted. Because we excluded complaints with questionable causes, numbers reported here differ from those previously reported (Fritts 1982, Fritts et al. 1992).

To complete analyses of the effectiveness of lethal control, we needed an experimental control to compare with farms at which lethal depredation control was conducted. However, a true experimental control, a sample of farms with verified depredations randomly chosen to receive no trapping, did not exist. Thus we created 2 reference groups, one with data from verified depredation sites where controllers trapped unsuccessfully and the second from farms with depredations but no trapping. Reasons for no trapping varied, so we selected only sites where given reasons would not seem to affect the analysis, such as the following: farmer denied permission, government manpower shortage, lack of funds, poor ground conditions, and too much hunter activity. If the reasons that complaints were not trapped included the following, we did not include them in our no-trapping reference sample: already trapping at a neighboring farm, stock removed from area, lone wolf responsible for depredation, or no reason given.

We used the no-trapping reference group because strong biases may exist in the data from both the successfully and unsuccessfully trapped farms. Farms with captured wolves may have more wolves around them than did farms with no captures, thus more likely sustaining repeat depredations regardless of number of wolves caught. Farms with no captures are more likely to have fewer wolves nearby and, thus, sustain fewer depredations. The no-trapping data set is not a perfect reference, but it was the best reference available.

We used the full database with released pups included to assess how often controllers captured wolves in response to a depredation by calculating percent of verified depredations where WS captured $\geq 1$ wolf.

\section{Distribution of Depredations Where Trapping Was Unsuccessful}

Previous studies yielded the counterintuitive conclusion that fewer subsequent depredations occurred where trapping was unsuccessful than where it was successful (Fritts 1982, Fritts et al. 1992). To determine if any pattern or bias could explain the apparent effectiveness of unsuccessful trapping, we assessed the temporal and geographical distributions of complaints trapped unsuccessfully. To assess temporal distribution, we graphed the percentage of total complaints each month at which trapping was unsuccessful to see if there was a seasonal effect.

To assess geographical distribution of apparent unsuccessful trapping, we used ArcView Geographic Information System software and its extension Animal Movement (P. N. Hooge and B. Eichenlaub, United States Geological Survey, Biological Science Center, Anchorage, AK) to map locations of depredated farms where trapping was unsuccessful both after single complaints and after multiple trapping events. We hypothesized that such farms might be in the path of dispersing wolves just passing through the area, so they would be located primarily on the edge of each year's depredation minimum convex polygon (MCP; see below). We then excluded all the unsuccessfully trapped farms along each year's MCP edges, allowing us to reexamine the effectiveness of unsuccessful trapping with the potential bias of farms affected by dispersing wolves removed. For complaints received 1 January-30 September, we calculated the percent with no more depredations the rest of the year, hypothesizing that excluding edge farms where no wolves were captured should decrease apparent effectiveness of unsuccessful trapping.

\section{Wolves Killed and Next Year's Depredations}

To assess if the number of wolves killed each year affected the number of depredations the next year, we computed 
correlations between number of wolves killed and number of depredations in the following year for the periods 19791998, 1979-1989, and 1989-1998 in response to verified cattle, sheep, or turkey depredations, as well as depredations on all domestic animals.

We also analyzed the data at 2 finer scales. For the first, we used data from 4 areas of historical depredations. To create these historical-depredation areas, we used ArcView to map the locations of farms with $\geq 1$ verified depredation each year from 1979 to 1998 and created yearly depredation MCPs including each year's farms (Fig. 1).

Using the depredation MCPs from 1989 through 1998, we created a new MCP of the area where all the MCPs overlapped (41,079 $\mathrm{km}^{2}$; Fig. 1). Using this common MCP, as well as the $1989 \mathrm{MCP}\left(53,232 \mathrm{~km}^{2}\right.$; Fig. 1), we examined the depredations inside the polygons, which allowed us to eliminate the effects of wolf range expansion (Harper et al. 2005). We examined these 2 MCPs because wolves have preyed on livestock there since 1989.

For an even finer scale, we used ArcView to locate 2 clusters of farms with long histories of depredations in an area of wolf depredations since 1979. We subjected one cluster, centered around a particular farm (farm A), to analyses using 3 data sets: 1) the data from 3 farms, 2) the data from 4 farms, and 3) the data from all 9 farms within 10 $\mathrm{km}$ of farm A. Each farm had a history of depredations. The second cluster consisted of 8 farms all centered around and within $10 \mathrm{~km}$ of a different farm (farm E), all with a history of depredations.

Use of these farm-cluster combinations also eliminated the effects of wolf range expansion. The $10-\mathrm{km}$ limit to the radius of the farm clusters and the territorial nature of wolves decreased the probability that increased depredations were caused by an increased number of wolf packs nearby. Use of 2 of the farm clusters also eliminated the effects that any increase in the numbers of farms sustaining depredations could have on the analysis.

\section{Depredation Recurrence Rate}

To study the effects that different variables had on time to next depredation, we computed the number of days between the date the last wolf was removed from a farm and the date of the next verified depredation. Our hypothesis was that killing wolves would increase the time to next depredation, or equivalently decrease the depredation recurrence rate. We used 3 geographic scales. We found time to next depredation at the same farm $(0 \mathrm{~km})$, at any farm within $4 \mathrm{~km}$, or at any farm within $8 \mathrm{~km}$. We used the locations of the farms to determine distances, essentially treating each farm as a point and ignoring barriers like roads or rivers. If no further depredations occurred, or if the next depredation was too far in the future, we considered the observation as censored. We used 2 rules for censoring. Under the 1-year rule we censored the observation at 365 days if no depredation occurred in that period. Under the 31 October rule we considered only depredations that occurred from 1 March to 31 October of a given year, and then recurrence only to 31 October of that year. This approach removed 50

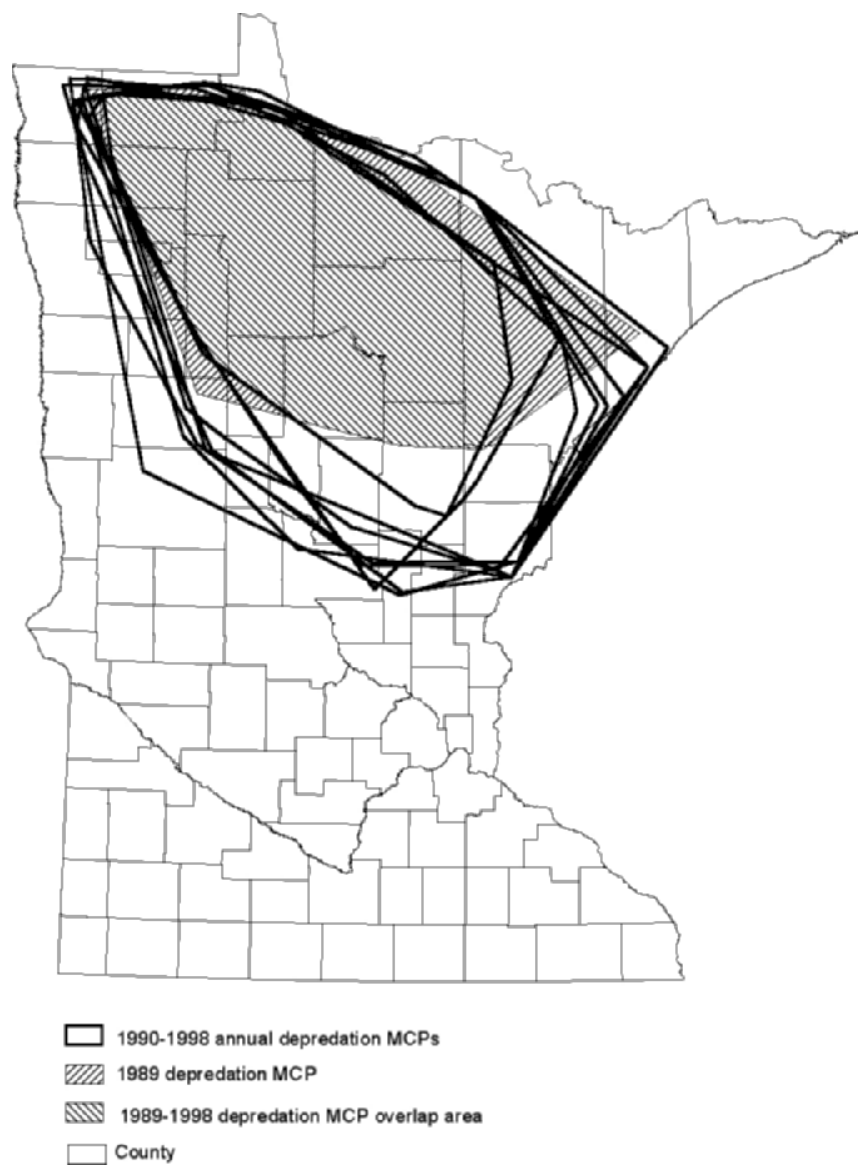

Figure 1. Yearly depredation minimum convex polygons (MCP) of locations of Minnesota, USA, farms with at least one verified cattle, sheep, or turkey depredation in 1990-1998 and shaded polygons representing the 1989 depredation MCP and the MCP where the 1989-1998 depredation MCPs overlap.

of the depredations between 1 November and 28 February from the study, but it corresponds to the goal of assessing reduction of re-depredations in the current year.

As is usual for censored data, the variables for each depredation consisted of a time and a censoring indicator. We used the Kaplan-Meier product-moment estimators (Kalbfleisch and Prentice 1980) to provide graphical summaries of the time-to-next depredation curves. We used Cox proportional-hazard models to test significance (Kalbfleisch and Prentice 1980). The proportional hazards model assumes the existence of a baseline time-to-redepredation curve that is modified by multiplication by $\exp \left(\sum \beta x\right)$, where each $x$ is a predictor and the $\beta$ s are regression coefficients. We considered a number of predictors. To adjust for seasonal effects, we included trigonometric predictors $\sin (2 \pi m / 12)$ and $\cos (2 \pi m / 12)$, where $m$ is the month number in all models. We also used a factor to account for effects of prey species (cow, sheep, or turkey). We included trapping outcome, including whether trapping was done, whether trapping was successful, and, if successful, age and sex of all wolves removed, in various combinations to be described in the results section below. We considered age and sex of wolves killed because some ages, sexes, or pack sizes of wolves might be more prone to 
Table 1. Trapping success of wolf-depredation control program in Minnesota, USA, by prey species, 1979-1998.

\begin{tabular}{lcccc}
\hline Species & $\begin{array}{c}\text { No } \\
\text { trapping }\end{array}$ & $\begin{array}{c}\text { Unsuccessful } \\
\text { trapping }\end{array}$ & $\begin{array}{c}\text { Successful } \\
\text { trapping }\end{array}$ & $\begin{array}{c}\text { Success } \\
\text { rate }\end{array}$ \\
\hline Cattle & 21 & 264 & 433 & 0.62 \\
Sheep & 15 & 66 & 64 & 0.49 \\
Turkey & 2 & 30 & 28 & 0.48 \\
Overall & 38 & 360 & 525 & 0.59 \\
\hline
\end{tabular}

preying on livestock. For example, wolf packs with pups may depend more on livestock (Bjorge 1980), or removal of some wolves could make others more dependent on livestock (Bjorge and Gunson 1985, Fritts et al. 1992). We used standard model selection methods in combination with Akaike's Information Criterion (AIC) to select appropriate predictors. We repeated the analysis for the 3 distances $(0$ $\mathrm{km}, 4 \mathrm{~km}$, and $8 \mathrm{~km}$ ) and for the 2 time-censoring rules.

For these analyses, we removed 4 depredations from the data base. One depredation had inconsistent dates in the original records. Three of the re-depredations occurred within 4 days of the original complaint, before any trapping could be initiated. Including these latter 3 cases would exaggerate differences between the no-trapping group and the unsuccessful and successful ( $\geq 1$ wolf removed) trapping groups.

\section{RESULTS}

Cattle and sheep in Minnesota are generally confined and not subject to wolf depredations from November to April or May, so wolves preyed on livestock primarily in May

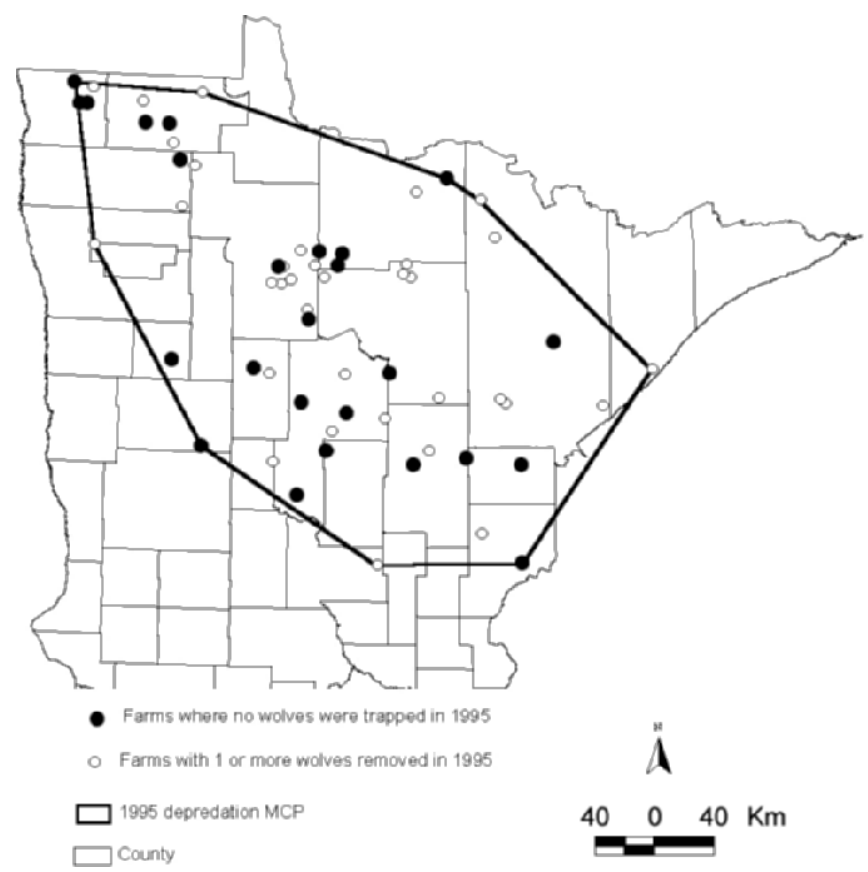

Figure 2. Distribution of Minnesota, USA, farms within the 1995 depredation minimum convex polygon where no wolves and where $\geq 1$ wolf was removed in 1995 during individual trapping sessions (1995 data are shown as an example).

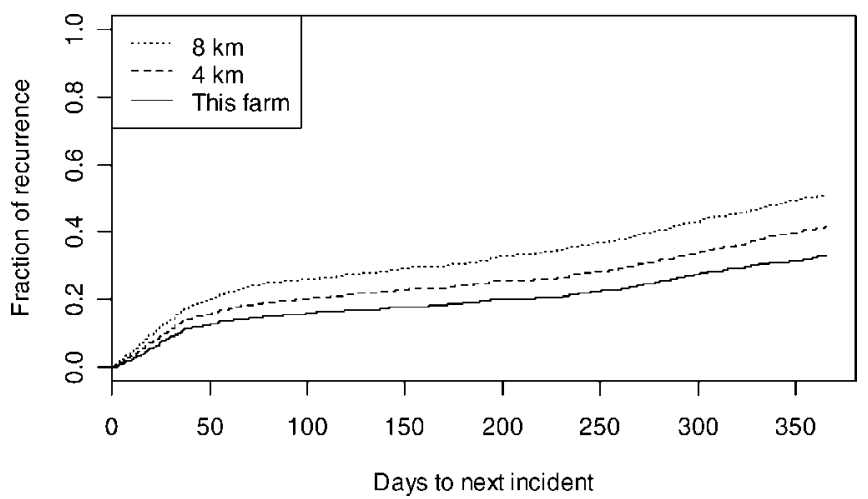

Figure 3. Wolf livestock-depredation recurrence curves for the current farm, within $4 \mathrm{~km}$ and within $8 \mathrm{~km}$, estimated using the Kaplan-Meier method on Minnesota, USA, farms, 1979-1998, for the following year, including all complaints whether or not trapping was conducted or successful.

through September as also reported earlier (Fritts 1982, Fritts et al. 1992).

When federal personnel responded to depredations with directed, lethal control, they succeeded trapping $\geq 1$ wolf at sheep or turkey farms about $48 \%$ of the time, and at cattle farms $62 \%$ of the time (Table 1). Overall trapping success was $59 \%$, somewhat higher than the $53 \%$ for $1979-1986$ (Fritts et al. 1992). Trapping was more successful in AprilJuly $(65 \%)$ than in the rest of the year $(52 \% ; P<0.001)$, probably due to reduced effort (seasonal leave), poor weather, or trap shyness. Unsuccessful trapping was not concentrated in any particular area (Fig. 2).

All 24 correlations we tested between number of wolves killed and next year's depredations for all periods and areas, for individual livestock, and all livestock combined showed either more depredations the next year or were nonsignificant $(P>0.10)$. The only marginally significant negative relationship was for all livestock across the entire state for $1989-1998\left(r^{2}=0.34 ; P=0.10\right)$.

\section{General Depredation Recurrence Rate}

When we pooled depredations on all species of livestock, the overall rate of recurrence in the same year was quite low. Using 365-day recurrences, at 250 days postdepredation the recurrence rate was estimated to be $23 \%(95 \% \mathrm{CI}=20$ $25 \%)$ at the farm level, $29 \%(95 \% \mathrm{CI}=25-32 \%)$ within 4 $\mathrm{km}$ of the farm, and $37 \%(95 \% \mathrm{CI}=34-40 \%)$ within $8 \mathrm{~km}$ of the farm (Fig. 3). Changing the follow-up to 31 October of the current year did not cause any changes in conclusions although the curves and rates are a bit different. When we considered livestock species separately, the re-depredation rates were higher for sheep and turkey than for cattle (Fig. 4). However, most depredations involved cattle.

The separate overall recurrence curves for each of 4 trapping outcomes (no trapping, unsuccessful trapping, successful trapping without removal of an ad $M$, and successful trapping with removal of an ad M) showed that the recurrence rate for no trapping was higher than for the other conditions. Figure 5 is typical of the figures for different distances and censoring rules. Except when no 


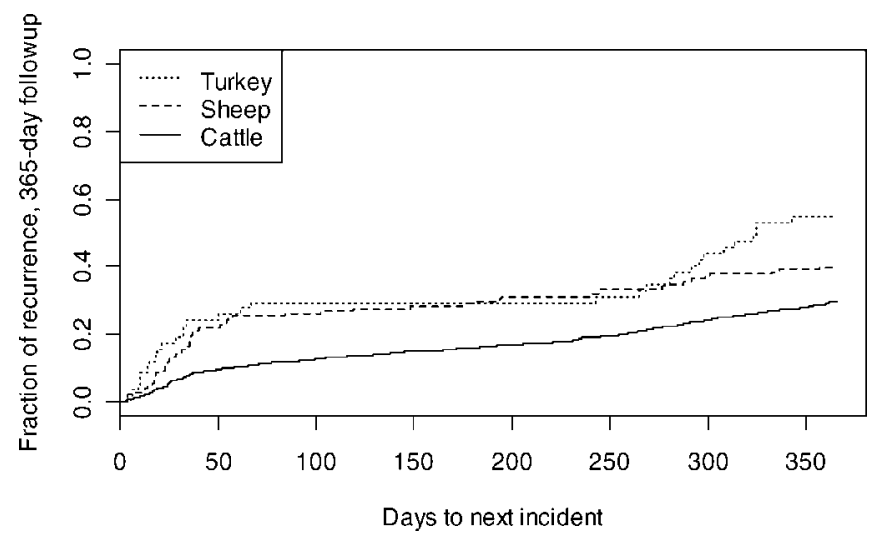

Figure 4. Rate of wolf livestock-depredation recurrences on Minnesota, USA, farms, 1979-1998, including all complaints whether or not trapping was conducted or successful, by type of prey species.

trapping was done, the rates in the other conditions were similar, with the recurrence rate when an adult male was removed the lowest, the rate for unsuccessful trapping the highest, and the rate for other successful trapping intermediate.

\section{Proportional Hazards Models}

With the possible exception of removing an adult male, age and sex of wolves killed had no effect on re-depredation rates. In addition, total number of animals removed did not appear to affect the re-depredation rate. We therefore report the results of fitting Cox proportional hazards models at the 3 geographic scales and using 2 censoring rules with 2 predictors for the seasonal trend, a factor with 3 levels for livestock species, and another factor with 4 levels for the outcome of trapping, including no trapping, unsuccessful trapping, successful trapping but no adult male(s) removed, and successful trapping with adult male(s) removed. All the models are parameterized so the baseline species is cattle, and the baseline trapping outcome is no trapping (Table 2).

Species differences are apparent at all geographic scales. At $0 \mathrm{~km}$ and $4 \mathrm{~km}$ for either censoring rule coefficient estimates for the trapping groups were all negative, indicating that trapping, regardless of outcome, reduces re-depredation, although differences are generally small. With 365-day follow-up at $0 \mathrm{~km}$, the unsuccessful trapping re-depredation rate was lower than the no trapping rate, with $P=0.04$; for 31 October censoring, the rate for trapping an adult male was lower, $P=0.04$ than the no trapping rate. According to the fitted model, the re-depredation rate $(95 \% \mathrm{CI})$ when an adult male was killed was $0.20-0.97$ times the redepredation rate for no trapping. At $8 \mathrm{~km}$, trapping did not appear to have any effect.

With data for sheep only, there was some evidence that successful trapping led to lower recurrence rates than did no trapping or unsuccessful trapping $(P=0.04-0.06)$.

\section{DISCUSSION}

The depredation peak we found for cattle in May corresponds with the availability of newborn calves, and a slight decrease in June may be related to availability of deer

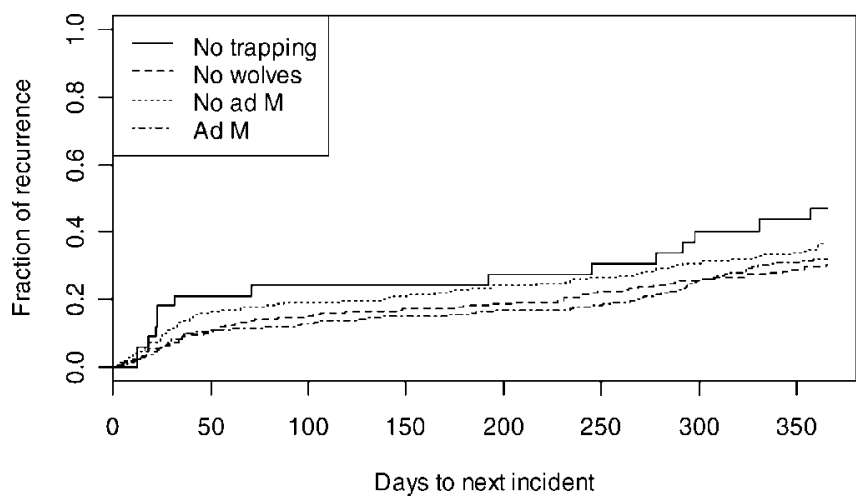

Figure 5. Rate of wolf livestock-depredation recurrences on Minnesota, USA, farms, 1979-1998, for all livestock combined comparing 4 groups of trapping outcome: no trapping, unsuccessful trapping, successful trapping with no adult males caught, and successful trapping with an adult male caught.

fawns born in June (Mech et al. 1988, Fritts et al. 1992). Increases over summer may be due to pups' increasing need for food (Fritts et al. 1992). In Alberta, Canada, cattle losses to wolves peaked in August-September (Dorrance 1982), perhaps due to the seasonal differences between the 2 areas or to differing seasonal livestock practices.

Unsuccessful trapping was not concentrated in any particular area (Fig. 2), contrary to our hypothesis that farms where trapping was unsuccessful were primarily along the edge of each year's depredation MCP. Thus not all cases of unsuccessful trapping involved dispersing wolves killing livestock and moving on, although some may have.

None of our correlations supported the hypothesis that killing a high number of wolves reduced the following year's depredations at state or local levels. This finding was similar to that of Fritts et al. (1992) for 1979-1986 data for all types of livestock depredations combined. Fritts et al. (1992) felt that their finding may have resulted from pooling data from farms with repeated depredations and new farms sustaining depredations. We did not find this to be true, however. Our analyses of localized farm clusters showed that as more wolves were killed one year, the depredations increased the following year. Examination of these localized farm clusters also eliminated the possibility that it was an increase in numbers of farms sustaining depredations that contributed to the findings that killing wolves did not reduce depredations the next year at local or state levels.

A possible explanation for the positive relationship between number of wolves killed and higher depredations was that farms where more wolves were captured may have been farms where more wolves lived. A second possibility is that any wolves remaining after trapping had learned to prey on livestock, possibly becoming more dependent on livestock once packmates have been removed. Harper et al. (2005) presented evidence for learned depredation behavior in wolves.

For all analyses, trapping but catching no wolves led to lower recurrence than not trapping at all (e.g., Fig. 5) which suggests that the mere increase in human activity and the introduction of foreign odor and objects at a depredation 
Table 2. Cox proportional-hazards survival-model results for recurrences of wolf-depredation control in Minnesota, USA, 1979-1998. Shown are coefficient estimates and significance levels when fitting seasonal adjustments, represented by the sin and cos terms, a factor for livestock species, and a factor with 4 levels for trapping outcome. Results are shown for 365-day follow-up and for follow-up until 31 October of the current year, and at 3 geographic scales, 0 km for the farm where depredation originally occurred and farms within $4 \mathrm{~km}$ and $8 \mathrm{~km}$ of that farm. Models are parameterized so that the baseline condition is for no trapping when the livestock species is cattle. Thus, probabilities for sheep and turkeys compare these conditions to those for cattle, and those for the 3 trapping outcomes compare to those for no trapping.

\begin{tabular}{|c|c|c|c|c|c|c|}
\hline & \multicolumn{2}{|c|}{$0 \mathrm{~km}$} & \multicolumn{2}{|c|}{$4 \mathrm{~km}$} & \multicolumn{2}{|c|}{$8 \mathrm{~km}$} \\
\hline & Estimate & $P$ & Estimate & $P$ & Estimate & $P$ \\
\hline \multicolumn{7}{|l|}{ 365-day follow-up } \\
\hline $\sin m$ & 0.144 & 0.140 & 0.080 & 0.360 & 0.114 & 0.140 \\
\hline $\cos m$ & -0.145 & 0.220 & -0.151 & 0.150 & -0.128 & 0.180 \\
\hline Sheep & 0.494 & 0.002 & 0.228 & 0.120 & 0.128 & 0.340 \\
\hline Turkey & 0.919 & 0.000 & 0.740 & 0.000 & 0.596 & 0.001 \\
\hline No wolves caught & -0.573 & 0.041 & -0.482 & 0.073 & -0.259 & 0.300 \\
\hline No ad M caught & -0.301 & 0.290 & -0.280 & 0.300 & -0.192 & 0.450 \\
\hline Ad M caught & -0.517 & 0.073 & -0.493 & 0.074 & -0.336 & 0.190 \\
\hline \multicolumn{7}{|l|}{ Follow-up to $31 \mathrm{Oct}$} \\
\hline $\sin m$ & 0.416 & 0.003 & 0.277 & 0.026 & 0.269 & 0.014 \\
\hline $\cos m$ & -0.387 & 0.097 & -0.382 & 0.066 & -0.489 & 0.010 \\
\hline Sheep & 1.217 & 0.000 & 0.874 & 0.000 & 0.625 & 0.000 \\
\hline Turkey & 1.269 & 0.000 & 1.030 & 0.000 & 0.924 & 0.000 \\
\hline No wolves caught & -0.541 & 0.160 & -0.657 & 0.056 & -0.369 & 0.270 \\
\hline No ad M caught & -0.296 & 0.440 & -0.496 & 0.150 & -0.388 & 0.260 \\
\hline Ad M caught & -0.808 & 0.043 & -0.888 & 0.013 & -0.614 & 0.076 \\
\hline
\end{tabular}

site might have been enough to reduce future depredations. Conceivably, then, any apparent decreases in depredation from killing wolves may actually have been due to increased human activity instead, although this would not explain why killing adult males in certain cases was most effective. Human activity may also at least partly explain the effectiveness of fladry (plastic flagging hanging on fencing surrounding farms) as a barrier to wolf depredations. Fladry reportedly kept wolves out of a cattle pasture for 61 days before wolves crossed the barrier and killed livestock (Musiani et al. 2003). Waning of the aversive response to the fladry could have been caused by habituation to the fladry or to the human scent.

There was no evidence that killing wolves decreased redepredation rates at farms within $8 \mathrm{~km}$ of an original depredation. For complaints involving cattle and turkeys, there was little evidence that killing wolves affected the redepredation rate any more than did unsuccessful trapping, contrary to our hypothesis. Nevertheless, attempting to trap seemed to provide some effectiveness. At the individual farm level and within $4 \mathrm{~km}$, targeting adult males and continuing to trap if they are believed present may have improved control effectiveness. This result accords with the findings that, at least in summer, the adult male tends to take the initiation in hunting (Mech 1999).

For depredations on sheep, killing wolves was more effective than unsuccessful trapping or not trapping, similar to Fritts et al. (1992). Sheep are more vulnerable to wolf depredation than are cattle, because sheep usually flock and are defenseless against wolves, so wolves may continue to return for sheep, whereas cattle depredations may be more single-event opportunities.

Conceivably, husbandry practices and habitats at farms included in our analysis could have changed over time, confounding our results. However, wolf depredations seem to be linked to farm size, with larger farms having more depredations (Mech et al. 2000, Bradley and Pletscher 2005), and some township-level habitat variables and prey densities at farm and township levels may also affect depredation (Treves et al. 2004, Bradley and Pletscher 2005).

\section{MANAGEMENT IMPLICATIONS}

Lethal wolf control for depredation on sheep in Minnesota is generally effective in reducing further losses. However, for reducing depredations on cattle $\geq 1$ adult male must be killed. Furthermore, experimenting with a regimen of daily visits simulating trapping activities might show that such an approach is more cost-effective than trapping and killing wolves, especially at farms that require long travel by controllers.

\section{ACKNOWLEDGMENTS}

This research was supported by the Biological Resources Division, United States Geological Survey, the United States Department of Agriculture Wildlife Services, and a donation by V. Gates to help support the senior author.

\section{LITERATURE CITED}

Berg, W., and S. Benson. 1999. Updated wolf population estimate for Minnesota, 1997-1998. Minnesota Department of Natural Resources, Grand Rapids, USA.

Bjorge, R. R. 1980. Management and research of the wolf-livestock conflict in Alberta. Pages 71-75 in Proceedings of the 27th Annual Meeting of the Canadian Pest Management Society, 4-6 August 1980, Edmonton, Alberta, Canada.

Bjorge, R. R., and J. R. Gunson. 1985. Evaluation of wolf control to reduce cattle predation in Alberta. Journal of Range Management 38:483-487.

Bradley, E. H., and D. H. Pletscher. 2005. Assessing factors related to wolf 
depredation of cattle in fenced pastures in Montana and Idaho. Wildlife Society Bulletin 33:1256-1265.

Dorrance, M. J. 1982. Predation losses of cattle in Alberta. Journal of Range Management 35:690-692.

Fritts, S. H. 1982. Wolf depredation on livestock in Minnesota. U.S. Fish and Wildlife Service, Resource Publication 145, Washington, D.C., USA.

Fritts, S. H., W. J. Paul, L. D. Mech, and D. P. Scott. 1992. Trends and management of wolf-livestock conflicts in Minnesota. U.S. Fish and Wildlife Service, Resource Publication 181, Washington, D.C., USA.

Fuller, T. K., W. E. Berg, G. L. Radde, M. S. Lenarz, and G. B. Joselyn. 1992. A history and current estimate of wolf distribution and numbers in Minnesota. Wildlife Society Bulletin 20:42-55.

Haight, R. G., L. E. Travis, K. Nimerfro, and L. D. Mech. 2002. Computer simulation of wolf-removal strategies for animal damage control. Wildlife Society Bulletin 30:844-852.

Harper, E. K., W. J. Paul, and L. D. Mech. 2005. Causes of wolf depredation increase in Minnesota from 1979 to 1998. Wildlife Society Bulletin 33:888-896.

Kalbfleisch, J. D., and R. L. Prentice. 1980. The statistical analysis of failure time data. Wiley, New York, New York, USA.

Mech, L. D. 1970. The wolf: the ecology and behavior of an endangered species. Natural History Press, Garden City, New York, USA.

Mech, L. D. 1986. Wolf population in the central Superior National Forest, 1967-1985. U.S. Forest Service Research Paper NC-270, St. Paul, Minnesota, USA.

Mech, L. D. 1998. Estimated costs of maintaining a recovered wolf population in agricultural regions of Minnesota. Wildlife Society Bulletin 26:817-822.

Mech, L. D. 1999. Alpha status, dominance, and division of labor in wolf packs. Canadian Journal of Zoology 77:1196-1203.

Mech, L. D. 2001. Managing Minnesota's recovered wolves. Wildlife Society Bulletin 29:70-77.

Mech, L. D., S. H. Fritts, and M. E. Nelson. 1996. Wolf management in the 21st century: from public input to sterilization. Journal of Wildlife Research 1:195-198.

Mech, L. D., S. H. Fritts, and W. J. Paul. 1988. Relationship between winter severity and wolf depredations on domestic animals in Minnesota. Wildlife Society Bulletin 16:127-130.

Mech, L. D., E. K. Harper, T. J. Meier, and W. J. Paul. 2000. Assessing factors that may predispose Minnesota farms to wolf depredations on cattle. Wildlife Society Bulletin 28:623-629.

Musiani, M., C. Mamo, L. Boitani, C. Callaghan, C. Gates, L. Mattei, E. Visalberghi, S. Breck, and G. Volpi. 2003. Wolf depredation trends and the use of fladry barriers to protect livestock in Western North America. Conservation Biology 17:1538-1547.

Paul, W. J. 2001. Wolf depredation control in Minnesota. International Wolf 11(3):11-12.

Treves, A., L. Naughton-Treves, E. K. Harper, D. J. Mladenoff, R. A. Rose, T. A. Sickley, and A. P. Wydeven. 2004. Predicting humancarnivore conflict: a spatial model derived from 25 years of data on wolf predation on livestock. Conservation Biology 18:114-125.

Associate Editor: Strickland. 